\title{
Dysregulation of AKT3 along with a small panel of mRNAs stratifies high-grade serous ovarian cancer from both normal epithelia and benign tumor tissues
}

\author{
Pourya Naderi Yeganeh ${ }^{1}$, Christine Richardson ${ }^{2}$, Zahra Bahrani-Mostafavi ${ }^{3}$, David \\ L. Tait ${ }^{4}$, M. Taghi Mostafavi ${ }^{1}$ \\ ${ }^{1}$ College of Computing and Informatics, University of North Carolina at Charlotte, Charlotte, NC, USA \\ ${ }^{2}$ Department of Biological Sciences, University of North Carolina at Charlotte, Charlotte, NC, USA \\ ${ }^{3}$ College of Health and Human Services, University of North Carolina at Charlotte, Charlotte, NC, USA \\ ${ }^{4}$ Division of Gynecological Oncology and Obstetrics, Levine Cancer Institute, Carolinas Medical Center, Charlotte, NC, USA \\ Correspondence to: M. Taghi Mostafavi, email: taghi@uncc.edu \\ Keywords: ovarian cancer, AKT3, genomic analysis, high-grade serous ovarian cancer, biomarker discovery \\ Received: September 20,2017 Accepted: December 01,2017 Published: December 29, 2017
}

\section{ABSTRACT}

Screening methods of High-Grade Serous Ovarian Cancer (HGSOC) lack specificity and sensitivity, partly due to benign tumors producing false-positive findings. We utilized a differential expression analysis pipeline on malignant tumor (MT) and normal epithelial (NE) samples, and also filtered the results to discriminate between MT and benign tumor (BT). We report that a panel of 26 dysregulated genes stratifies MT from both BT and NE. We further validated our findings by utilizing unsupervised clustering methods on two independent datasets. We show that the 26-genes panel completely distinguishes HGSOC from NE, and produces a more accurate classification between HGSOC and BT. Pathway analysis reveals that AKT3 is of particular significance, because of its high fold change and appearance in the majority of the dysregulated pathways. mRNA patterns of AKT3 suggest essential connections with tumor growth and metastasis, as well as a strong biomarker potential when used with 3 other genes (PTTG1, MND1, CENPF). Our results show that dysregulation of the 26-mRNA signature panel provides an evidence of malignancy and contribute to the design of a high specificity biomarker panel for detection of HGSOC, potentially in an early more curable stage.

\section{INTRODUCTION}

Ovarian cancer is the leading cause of death among gynecological cancers and early diagnosis is one of the key challenges in reducing the mortality rate [1-3]. Early detection strategies of ovarian cancer lack required specificity and sensitivity, leading to diagnosis in advanced and more lethal stages in $75 \%$ of patients $[4,5]$. For example, elevations of the biomarker Cancer Antigen 125 (CA125) produce a relatively small true positive rate for early stage ovarian cancers, while the false positive rates are high for patients with benign tumors and noncancerous subjects [5, 6]. Major clinical trials -- Prostate, Lung, Colon, and Ovarian (PLCO) screening trials, and UK Collaborative Trial of Ovarian Cancer Screening (UKTOCS) - indicate that the current screening strategies do not contribute to the reduction of mortality rates $[7$,
8]. Not surprisingly, the design and discovery of credible biomarker panels for detection of ovarian cancer has emerged as a formidable task.

To date, genome-scale comparative studies have considerably contributed to the discovery of new markers, therapeutic targets, cancer subtypes, and origins of ovarian cancer. [9-13]. The utilization of genomic scale analyses has also substantially benefited the characterization of malignant tumors [14, 15]. However, many of the genetic and pathological features associated with cancer also occur in benign tumors, including some of the hallmarks of cancer, such as evading growth suppressors and resisting cell death [14-16]. The molecular and pathological resemblance between malignant and nonmalignant tumors is a barrier in the design of cancerfocused detection and treatment approaches [16]. Given these challenges, the identification of malignancy-specific 
molecular signatures plays a critical role in the disease diagnosis and management.

This study focuses on identification of a molecular signature panel in High-Grade Serous Ovarian Cancer (HGSOC) which constitutes up to $80 \%$ of the cases of ovarian cancer [17]. We focus on the discovery of a small signature panel of mRNA markers that can differentiate between malignant and benign tumors. We hypothesize that comparative mRNA analysis of ovarian tissues would reveal critical signatures of malignancy and tumor progression in HGSOC. To probe our hypothesis, we investigated the gene expression profiles of distinct ovarian tissues by utilizing Laser Capture Microdissection (LCM) for high sample purity [18]. We analyzed the mRNA expression levels of normal ovarian epithelia (NE), benign ovarian tumors (BT), and HGSOC malignant tumors (MT). Analyses were performed to capture the differential expressions patterns, similar to Bowen et al. [9] who utilized a related design and identified ovarian surface epithelial markers in the cancer tumors. Our experimental design uniquely included BT samples which allowed for a more comprehensive molecular characterization of the different pathological states [16]. Our results identify a small signature mRNA panel of 26 dysregulated genes that stratifies MT from both BT and NE. Validity of the identified panel was verified by using classification algorithms on two publicly available independent datasets (GSE9899 and GSE14407) [9, 12]. To determine the functional properties of the dysregulated genes in the active programs of HGSOC, we compared results from pathway enrichments and the mRNA dysregulation between MT and BT.

\section{RESULTS}

\section{Differential mRNA expression analysis of normal epithelia versus malignant tumors:}

Analysis of MT and NE samples (Table 1) detects 216 significantly differentially expressed genes, 100 of which are upregulated and 116 are downregulated (supplementary table). Table 2 details the 20 upregulated genes with greatest fold changes as well as the 20 downregulated genes with greatest fold changes. The analysis detects dysregulation of genes previously associated with HGSOC - such as Paired box 8 (PAX8), Paternally expressed 3 (PEG3), Survivin (BIRC5), Meis homeobox 1 (MEIS1), and Homeobox C6 (HOXC6) - as well as unreported ones, such as Meiotic nuclear divisions 1 (MND1), and Protein Kinase B, Gamma (AKT3), (Table 2 and supplementary table) [19-21].

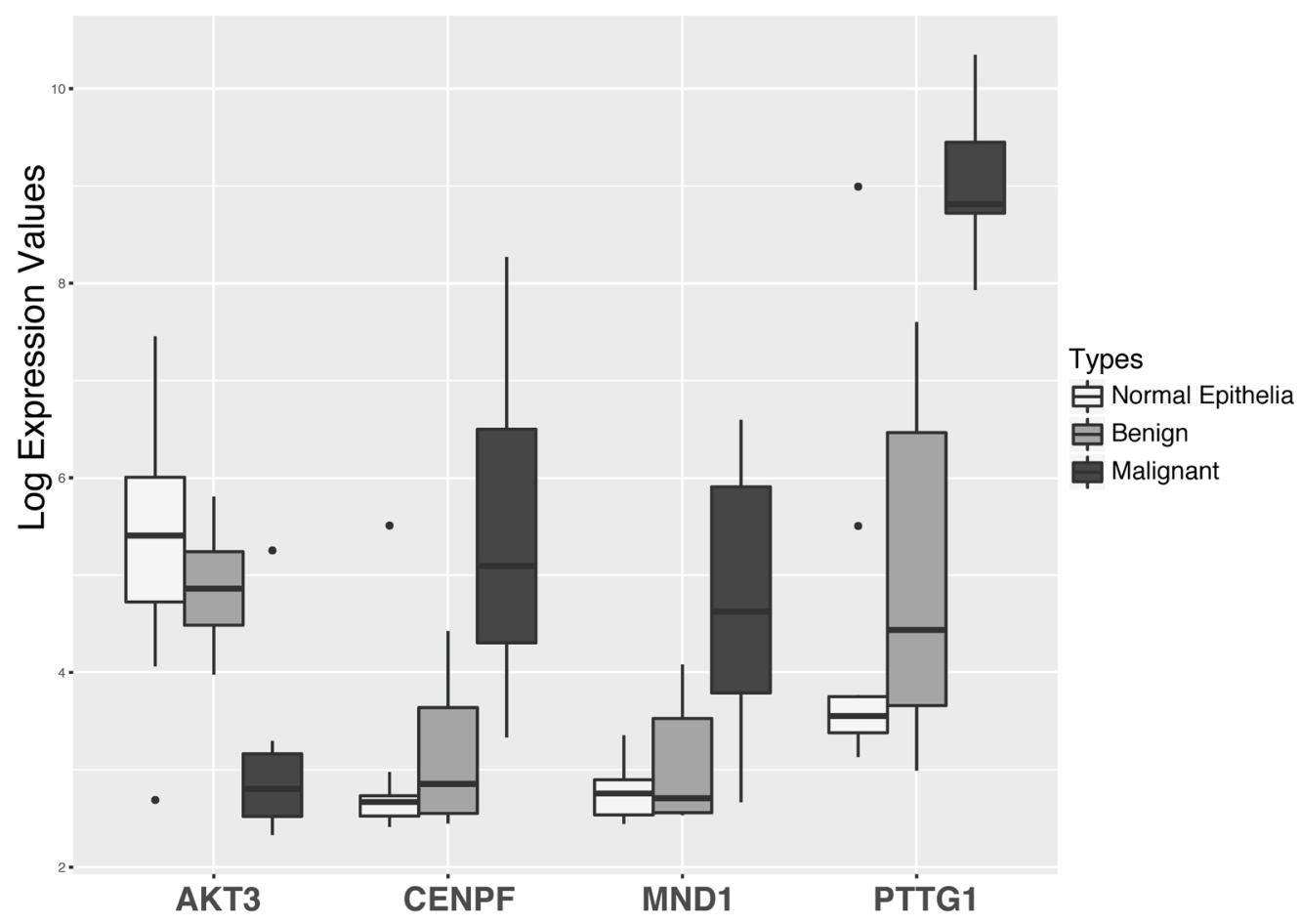

Figure 1: The expression patterns of AKT3, CENPF, MND1, and PTTG1 distinguish between normal ovarian epithelia, benign tumors, and malignant tumors. The expression data are obtained using microarray signals from LCM samples. The graph displays the differentially expressed genes with fold change magnitude more than 3 . Further confirmation is displayed in Figure 2. 
Table 1: Sample information used in the study

\begin{tabular}{|c|c|c|c|}
\hline Sample ID** & Tissue Type & Primary Pathology & Stage* \\
\hline $\mathrm{I}$ & Benign tumor tissue & Serous Cyst & --- \\
\hline II & Benign tumor tissue & Serous Cystadenofibroma & --- \\
\hline III & Benign tumor tissue & Serous Cyst & -- \\
\hline IV & Benign tumor tissue & Serous Cystadenofibroma & --- \\
\hline $\mathrm{V}$ & Benign tumor tissue & Serous Cyst & --- \\
\hline VI & Benign tumor tissue & Serous Cyst & --- \\
\hline VII & Malignant tumor tissue & Serous Carcinoma & II \\
\hline VIII & Malignant tumor tissue & Serous Carcinoma & IIIc \\
\hline IX & Malignant tumor tissue & Serous Carcinoma & IIIc \\
\hline $\mathrm{X}$ & Malignant tumor tissue & Serous Carcinoma & IIIc \\
\hline $\mathrm{XI}$ & Malignant tumor tissue & Serous Carcinoma & $\mathrm{NA}^{\wedge}$ \\
\hline XII & Malignant tumor tissue & Serous Carcinoma & IIIc \\
\hline XIII & Malignant tumor tissue & Serous Carcinoma & IIIc \\
\hline XIV & Malignant tumor tissue & Serous Carcinoma & IIIc \\
\hline $\mathrm{XV}$ & Normal ovarian epithelia & Non-tumorous & --- \\
\hline XVI & Normal ovarian epithelia & Malignant Serous Carcinoma & II \\
\hline XVII & Normal ovarian epithelia & Serous Cystadenofibroma & --- \\
\hline XVIII & Normal ovarian epithelia & Simple Serous Cyst & --- \\
\hline XIX & Normal ovarian epithelia & Metastatic Serous Carcinoma & IIIc \\
\hline $\mathrm{XX}$ & Normal ovarian epithelia & Metastatic Serous Carcinoma & IIIc \\
\hline XXI & Normal ovarian epithelia & Serous Cystadenofibroma & --- \\
\hline XXII & Normal ovarian epithelia & Metastatic Serous Carcinoma & --- \\
\hline XXIII & Normal ovarian epithelia & Metastatic Serous Carcinoma & --- \\
\hline XXIV & Normal ovarian epithelia & Metastatic Serous Carcinoma & IIIc \\
\hline
\end{tabular}

* Indicates the stage of the patients at the time of sample collection according to The International Federation of Gynecology and Obstetrics.

${ }^{\wedge}$ NA indicates unavailability of information regarding sample.

** Data from this study is accessible through NCBI's Gene Expression Omnibus through dataset GSE 29156.

\section{Dysregulated mRNA expressions between benign and malignant tumors:}

At the initial step of the analysis pipeline, 216 dysregulated genes were found between MT and NE. The dysregulated genes were then tested in another specific comparison pipeline. Of the 216 dysregulated genes 26 were detected as differentially expressed between MT and BT (Table 3). Among the 26 genes, AKT3, Human Securin encoding gene (PTTG1), Centromere protein F (CENPF), and MND1 exhibit fold change magnitudes of greater than 3 (Figure 1, Table 3). In MT vs. NE setting, AKT3 is downregulated by 4.68 folds (p-value $<2.99 \mathrm{E}-04$ ), and PTTG1, CENPF, and MND1 are all upregulated by 28.8 fold (p-value $<1.96 \mathrm{E}-06$ ), 5.9 fold (p-value $<2.1 \mathrm{E}-04$ ), and 3.9 fold (p-value $<1.29 \mathrm{E}-04$ ), respectively. In MT vs.
BT setting, the mRNA dysregulation of these four genes (AKT3, PTTG1, CENPF, and MND1) yield a similar statistically significant pattern (Table 3 ).

Cross-examination of expression of the set of four genes provides additional evidence for their dysregulation in HGSOC. Two independent and publicly available datasets by Tothill et al. (GSE9899) and Bowen et al. (GSE14407) (Figure 2) [9, 12] were utilized. In malignant tumors compared to Low Malignant Potential (LMP) tumors in GSE9899 dataset, AKT3 is downregulated by 2.1 folds (p-value < 0.0012); PTTG1, MND1, and CENPF are upregulated with 5.9 (p-value $<2.83$ E-19), 4.12 (p-value $9.9 \mathrm{E}-11$ ), and 3.17 folds (p-value $<1.67 \mathrm{E}$ 08 ), respectively. The dysregulation patterns persist in LCM-collected normal epithelia and malignant epithelial ovarian tissues (from GSE14407). AKT3 is downregulated by 5.7 folds (p-value < 4.11 E-06); PTTG1, MND1, and 
Table 2:Top 20 downregulated and upregulated genes in MT compared to NE.

\begin{tabular}{|c|c|c|c|c|c|c|c|}
\hline \multicolumn{4}{|l|}{ Downregulated Genes } & \multicolumn{4}{|l|}{ Upregulated Genes } \\
\hline Gene Symbol - Description & Ref Seq & P-value & $\mathbf{F C}^{\wedge \wedge}$ & Gene Symbol - Description & Ref Seq & P-value ${ }^{\wedge}$ & $\mathbf{F C}^{\wedge \wedge}$ \\
\hline *DCN - decorin & NM_133506 & $2.29 \mathrm{E}-05$ & -13.8 & $\begin{array}{l}\text { PTTG1 - pituitary tumor-trans- } \\
\text { forming } 1\end{array}$ & ENST00000352433 & $1.96 \mathrm{E}-06$ & 28.8 \\
\hline C7 - complement component 7 & NM_000587 & $2.78 \mathrm{E}-04$ & -10.0 & $\begin{array}{l}\text { MAL2 - mal, T-cell differentia- } \\
\text { tion protein } 2\end{array}$ & NM_052886 & 4.12E-08 & 26.5 \\
\hline $\begin{array}{l}\text { EFEMP1 - EGF containing } \\
\text { fibulin-like extracellular }\end{array}$ & NM_001039348 & $9.18 \mathrm{E}-07$ & -9.09 & CP - ceruloplasmin & NM_000096 & 6.64E-06 & 17.4 \\
\hline *THBS1-thrombospondin 1 & ENST00000260356 & $9.84 \mathrm{E}-05$ & -8.93 & $\begin{array}{l}\text { ESRP1 - epithelial splicing } \\
\text { regulatory protein } 1\end{array}$ & NM_017697 & 3.47E-06 & 14.6 \\
\hline PEG3 - paternally expressed 3 & NM_006210 & $4.34 \mathrm{E}-04$ & -8.11 & $\begin{array}{l}\text { LPAR3 - lysophosphatidic acid } \\
\text { receptor } 3\end{array}$ & NM_012152 & $6.50 \mathrm{E}-07$ & 12.2 \\
\hline MGP - matrix Gla protein & NM_001190839 & $3.94 \mathrm{E}-05$ & -5.68 & CD24 - CD24 molecule & NM_013230 & 2.27E-06 & 10.3 \\
\hline CDH11- cadherin 11 & ENST00000268603 & $2.24 \mathrm{E}-04$ & -5.67 & $\begin{array}{l}\text { VAMP8 - vesicle associated } \\
\text { membrane protein } 8\end{array}$ & NM_003761 & $3.41 \mathrm{E}-05$ & 9.8 \\
\hline $\begin{array}{l}\text { *AKT3 - protein kinase B, } \\
\text { gamma }\end{array}$ & NM_005465 & 2.99E-04 & -4.68 & $\begin{array}{l}\text { MECOM - MDS1 and EVI1 } \\
\text { complex locus }\end{array}$ & NM_001105077 & 2.61E-06 & 8.69 \\
\hline $\begin{array}{l}\text { ANTXR1 - anthrax toxin } \\
\text { receptor }\end{array}$ & NM_032208 & 7.10E-06 & -4.64 & $\begin{array}{l}\text { RPL39L - ribosomal protein } \\
\text { L39-like }\end{array}$ & ENST00000296277 & 0.000168 & 7.11 \\
\hline OLFML1 - olfactomedin-like 1 & ENST00000530135 & 4.79E-06 & -4.39 & $\begin{array}{l}\text { WFDC2 - WAP four-disulfide } \\
\text { core domain } 2\end{array}$ & ENST00000342873 & 4.99E-06 & 7.11 \\
\hline $\begin{array}{l}\text { ANTXR2 - anthrax toxin } \\
\text { receptor } 2\end{array}$ & ENST00000403729 & $1.48 \mathrm{E}-05$ & -4.09 & $\begin{array}{l}\text { SLC38A1 - solute carrier family } \\
38 \text {, member } 1\end{array}$ & NM_030674 & $2.13 \mathrm{E}-05$ & 6.41 \\
\hline CALD1- caldesmon 1 & NM_033138 & $7.66 \mathrm{E}-06$ & -4.08 & $\begin{array}{l}\text { SPINT2 - serine peptidase } \\
\text { inhibitor, Kunitz type, } 2\end{array}$ & NM_021102 & $3.68 \mathrm{E}-06$ & 6.36 \\
\hline $\begin{array}{l}\text { NEXN - nexilin (F actin bind- } \\
\text { ing protein) }\end{array}$ & NM_144573 & $3.55 \mathrm{E}-04$ & -4.07 & CLDN4 - claudin 4 & ENST00000435050 & 8.17E-09 & 6.13 \\
\hline $\begin{array}{l}\text { PTGIS - prostaglandin I2 (pros- } \\
\text { tacyclin) synthase }\end{array}$ & NM_000961 & $6.21 \mathrm{E}-04$ & -3.88 & CENPF- centromere protein F & NM_016343 & 0.000209 & 5.90 \\
\hline PLS3 - plastin 3 & NM_005032 & $6.44 \mathrm{E}-04$ & -3.85 & DPY30 - dpy-30 homolog & NM_032574 & 0.000260 & 5.79 \\
\hline $\begin{array}{l}\text { RHOBTB3 - Rho-related BTB } \\
\text { domain containing } 3\end{array}$ & NM_014899 & $4.78 \mathrm{E}-04$ & -3.76 & $\begin{array}{l}\text { XPR1 - xenotropic and poly- } \\
\text { tropic retrovirus }\end{array}$ & NM_004736 & $1.61 \mathrm{E}-05$ & 5.76 \\
\hline SDC2 - syndecan 2 & NM_002998 & $1.23 \mathrm{E}-04$ & -3.68 & $\begin{array}{l}\text { EPCAM - epithelial cell adhe- } \\
\text { sion molecule }\end{array}$ & NM_002354 & 3.34E-05 & 5.65 \\
\hline $\begin{array}{l}\text { CCDC80 - coiled-coil domain } \\
\text { containing } 80\end{array}$ & ENST00000206423 & $1.16 \mathrm{E}-04$ & -3.61 & BIRC5 - Survivin & AF077350 & 0.000429 & 5.61 \\
\hline SULF2 - sulfatase 2 & ENST00000359930 & $1.42 \mathrm{E}-04$ & -3.61 & $\begin{array}{l}\text { SCNN1A - sodium channel, } \\
\text { non-voltage-gated } 1\end{array}$ & NM_001038 & 7.50E-05 & 5.48 \\
\hline $\begin{array}{l}\text { TRPC1 - transient receptor } \\
\text { potential cation channel }\end{array}$ & NM_001251845 & $3.53 \mathrm{E}-05$ & -3.60 & DSP - desmoplakin & ENST00000379802 & 0.000238 & 5.41 \\
\hline $\begin{array}{l}\text { COL14A1 - ollagen, type XIV, } \\
\text { alpha } 1\end{array}$ & NM_021110 & $3.11 \mathrm{E}-05$ & -3.55 & MEIS1 - Meis homeobox 1 & NM_002398 & $5.20 \mathrm{E}-05$ & 5.20 \\
\hline
\end{tabular}

$\wedge$ P-values are calculated based on ANOVA method and all of the p-value were subjected to multiple hypothesis testing criteria $(\mathrm{FDR}<0.05)$.

$\wedge^{\wedge}$ Fold Change of Malignant versus Normal

* Genes are also present in the dysregulation network displayed in Figure 6.

CENPF are upregulated with 4.2 (p-value $<3.52$ E-05), 1.86 (p-value $<0.008$ ), and 5.78 folds (p-value $<1.87$ E-09), respectively. Although the experimental design and samples are different in each study, the displayed results validate the findings. The test datasets contain control samples from normal and benign ovarian tissues, and provide a suitable sample composition for validating our findings.

Enrichment analysis results of the 26 differentially expressed genes between MT and BT detects the terms cell cycle, regulation of mitotic cell cycle phase transition, regulation of cell cycle phase transition, E2F cell cycle related transcription factors, and $G 2 / M$ checkpoint in hallmarks. Common biological knowledge assumes that the malignant cells exhibit attributes indicating invasion and rapid cell growth compared to benign cells. PTTG1, CENPF, BIRC5, Enhancer of zeste homolog 2 (EZH2), Rac GTPase activating protein 1 (RACGAP1), and cell 
Table 3: List of the genes differentially expressed between MT compared to both BT and NE.

\begin{tabular}{|c|c|c|c|c|c|c|c|}
\hline \multicolumn{4}{|l|}{ Upregulated Genes } & \multicolumn{4}{|l|}{ Downregulated Genes } \\
\hline Gene Symbol - Description & Ref Seq & P-value & $\mathbf{F C}^{\wedge \wedge}$ & Gene Symbol - Description & Ref Seq & $\begin{array}{l}\text { P-val- } \\
\text { ue }^{\wedge}\end{array}$ & $\mathrm{FC}^{\wedge \wedge}$ \\
\hline $\begin{array}{l}\text { CDC7 - cell division cycle } 7 \\
\text { homolog }\end{array}$ & NM_001134420 & $6.58 \mathrm{E}-05$ & 2.64 & $\begin{array}{l}\text { BNIP3L- BCL2/ adenovirus } \\
\text { E1B 19kDa interacting protein } \\
\text { 3-like }\end{array}$ & ENST00000380629 & 0.00250 & -2.18 \\
\hline $\begin{array}{l}\text { PTTG1 - pituitary tumor- } \\
\text { transforming } 1\end{array}$ & ENST00000352433 & 9.69E-05 & 16.9 & DKK3 - dickkopf 3 homolog & AF400439 & 0.00320 & -1.52 \\
\hline $\begin{array}{l}\text { FDPS - farnesyl diphosphate } \\
\text { synthase }\end{array}$ & NM_001135821 & $9.90 \mathrm{E}-05$ & 2.51 & $\begin{array}{l}\text { *AKT3 - Protein Kinase B, } \\
\text { gamma }\end{array}$ & NM_005465 & 0.00565 & -3.50 \\
\hline $\begin{array}{l}\text { *RAB11FIP4 - RAB11 family } \\
\text { interacting protein } 4\end{array}$ & NM_032932 & 0.000201 & 1.42 & & & & \\
\hline $\begin{array}{l}\text { PITRM1 - pitrilysin metallopep- } \\
\text { tidase } 1\end{array}$ & NM_001242307 & 0.000391 & 2.36 & & & & \\
\hline $\begin{array}{l}\text { NAA40 - N(alpha)-acetyltrans- } \\
\text { ferase } 40\end{array}$ & ENST00000377793 & 0.000585 & 1.74 & & & & \\
\hline $\begin{array}{l}\text { *BCL11A - B-cell CLL/lym- } \\
\text { phoma 11A }\end{array}$ & NM_022893 & 0.000656 & 1.72 & & & & \\
\hline $\begin{array}{l}\text { PUS7 - pseudouridylate syn- } \\
\text { thase } 7 \text { homolog }\end{array}$ & ENST00000356362 & 0.000889 & 1.84 & & & & \\
\hline BIRC5 - Survivin & AF077350 & 0.000925 & 1.93 & & & & \\
\hline $\begin{array}{l}\text { TFB2M - transcription factor } \\
\text { B2, mitochondrial }\end{array}$ & ENST00000366514 & 0.00110 & 2.23 & & & & \\
\hline $\begin{array}{l}\text { PCGF1 - polycomb group ring } \\
\text { finger } 1\end{array}$ & ENST00000233630 & 0.00136 & 2.05 & & & & \\
\hline $\begin{array}{l}\text { EZH2 - Enhancer of zeste } \\
\text { homolog } 2\end{array}$ & NM_001203247 & 0.00173 & 2.53 & & & & \\
\hline $\begin{array}{l}\text { CENPF - Centromere protein } \\
\text { F }\end{array}$ & NM_016343 & 0.00181 & 5.01 & & & & \\
\hline $\begin{array}{l}\text { RACGAP1- Rac GTPase acti- } \\
\text { vating protein } 1\end{array}$ & NM_013277 & 0.00185 & 2.69 & & & & \\
\hline $\begin{array}{l}\text { MND1 - Meiotic nuclear divi- } \\
\text { sions } 1\end{array}$ & NR_045605 & 0.0020 & 3.20 & & & & \\
\hline $\begin{array}{l}\text { UBAP2L - ubiquitin associated } \\
\text { protein 2-like }\end{array}$ & NM_014847 & 0.0021 & 2.58 & & & & \\
\hline $\begin{array}{l}\text { HJURP - Holliday junction } \\
\text { recognition protein }\end{array}$ & NM_018410 & 0.00307 & 2.01 & & & & \\
\hline $\begin{array}{l}\text { LRRTM1 - LRRN4 C-terminal } \\
\text { like }\end{array}$ & ENST00000433224 & 0.00385 & 1.70 & & & & \\
\hline $\begin{array}{l}\text { MRPS18A-mitochondrial ribo- } \\
\text { somal protein S18A }\end{array}$ & NM_018135 & 0.00394 & 2.29 & & & & \\
\hline $\begin{array}{l}\text { PRKDC - protein kinase, DNA- } \\
\text { activated, catalytic polypeptide }\end{array}$ & NM_006904 & 0.00447 & 2.24 & & & & \\
\hline $\begin{array}{l}\text { POGK - pogo transposable ele- } \\
\text { ment with KRAB domain }\end{array}$ & ENST00000367875 & 0.00479 & 1.74 & & & & \\
\hline $\begin{array}{l}\text { TMEM206 -transmembrane } \\
\text { protein } 206\end{array}$ & ENST00000261455 & 0.00527 & 1.40 & & & & \\
\hline $\begin{array}{l}\text { CDK16 - cyclin-dependent } \\
\text { kinase } 16\end{array}$ & NM_006201 & 0.00556 & 2.26 & & & & \\
\hline
\end{tabular}

* Genes are also present in the dysregulation network displayed in Figure 6.

Bold indicates fold change more than $3 ; \mathrm{FC}^{\wedge \wedge}$ indicates fold change of Malignant versus Benign

division cycle 7 homolog (CDC7) are associated with G2M checkpoint (p-value <3.16 E-6). Similarly, BIRC5, EZH2, RACGAP1, PTTG1, and protein kinase, DNAactivated, catalytic polypeptide (PRKDC) are associated with E2F transcription factor cell cycle-related targets (p-value $<1.06$ E-4).

\section{A panel of 26 dysregulated genes distinguishes HGSOC tumors from normal and benign ovarian samples:}

The two datasets (GSE14407 and GSE9899) were used to investigate the utility of the 26 dysregulated genes (Table 3 ) as a mRNA panel to stratify malignant 
samples from benign and normal samples. Unsupervised hierarchical clustering of the mRNA panel on GSE9899 shows that LMP samples are clustered close together and separated from malignant samples (Figure 3A). Using a similar procedure on GSE14407 shows a clear distinction between the normal epithelial samples and malignant samples (Figure 3B).

Principal Component Analysis (PCA), followed by k-means clustering, was used to further assess the utility of the mRNA panel. PCA of GSE14407 samples shows that the use of the 26-genes mRNA panel is sufficient to stratify normal epithelial tissues from HGSOC (Table 4). The unsupervised k-means clustering separates the tissue types into two distinct groups with no overlap between their 95\% confidence ellipses, when only using the two first principal components (Figure 4). In contrast, a similar procedure fails to distinguish between the tissue types when the mRNA signature panel is not used for PCA; and finds an overlap between the 95\% confidence ellipses. When using the mRNA panel, the first two principal components explain more than $59.6 \%$ of the variance in the data, up from $48.9 \%$ when using all the genes for PCA.

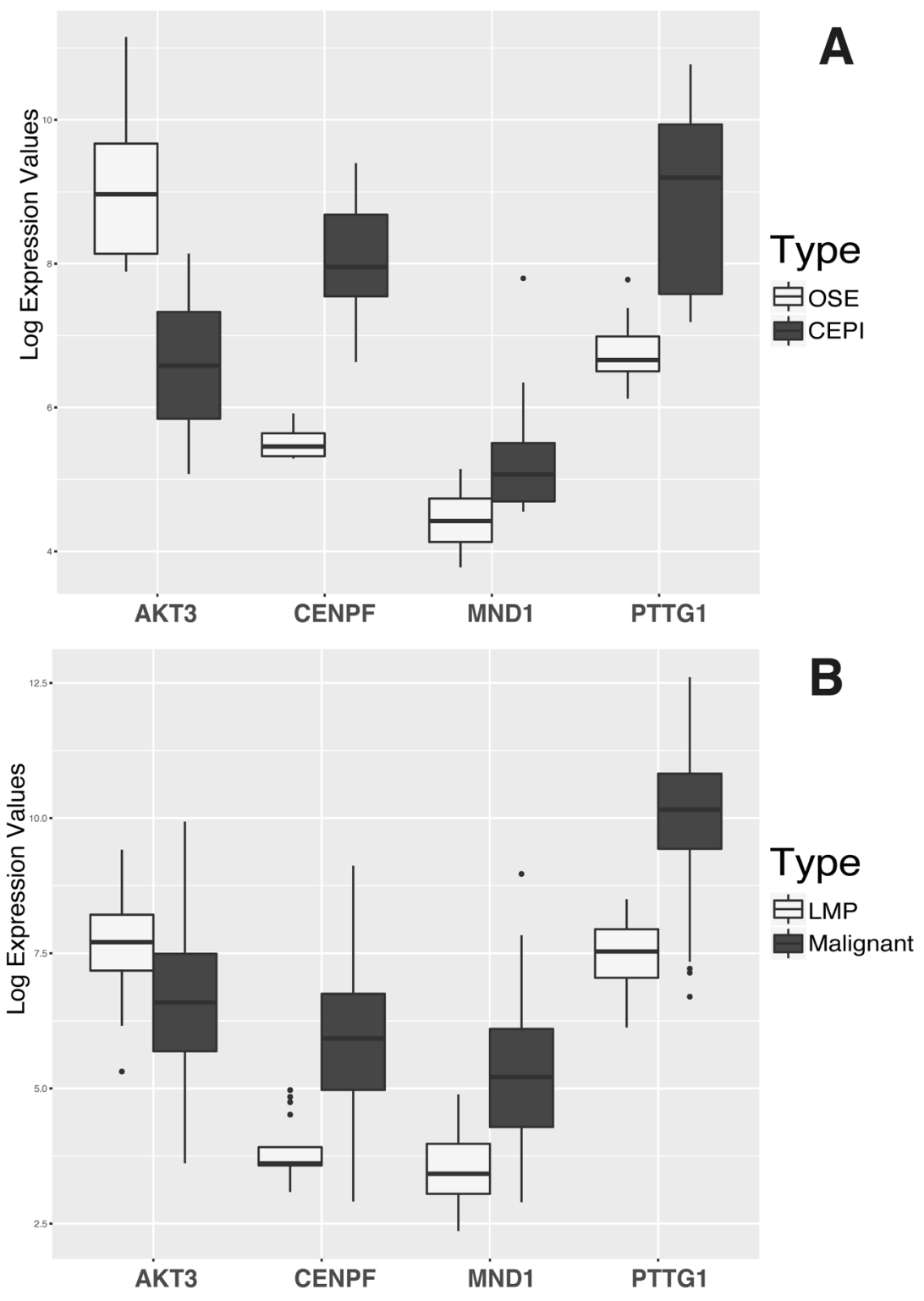

Figure 2: Evaluation of AKT3, CENPF, PTTG1, and MND1 differential expression using two independent datasets. A) Box plots are based on Tothill's data using 264 microarray samples of ovarian tumors with low potential malignant (LMP) samples and cancer tumors [12]. The lighter-shade boxplots represent the mRNA expression levels in LMP. Darker-shade boxplots represent the mRNA expression levels in malignant tumors. B) Box plots are based on Bowen's data with 12 LCM ovarian epithelia samples and 12 cancer tissues [9]. The lighter-shade boxplots represent the mRNA expression levels in normal ovarian epithelial tissues and the darker-shade boxplots represent mRNA expression levels in cancer tumors. Additional information on microarray analysis on both datasets can be found in supplementary material. 
PCA followed by k-means clustering on GSE9899 dataset shows that using the dysregulated mRNA panel produces a stronger classification compared to when using all genes (Figure 5). k-means clustering classifies LMP samples into the same group and associates a larger fraction of the malignant tumors to another group when using the 26-genes mRNA panel as a base. In contrast, using all genes' transcripts fails to discriminate between the two groups and distributes the tissue types in both of the clusters (Table 4). Also, using the mRNA panel increases the variance in data explained by PCA. The first two principal components explain $35.9 \%$ of the variance when using the 26-panel, up from $11.1 \%$ when using no panel (Figure 5).

\section{Hierarchical Clustering of HGSOC Microarray Data}
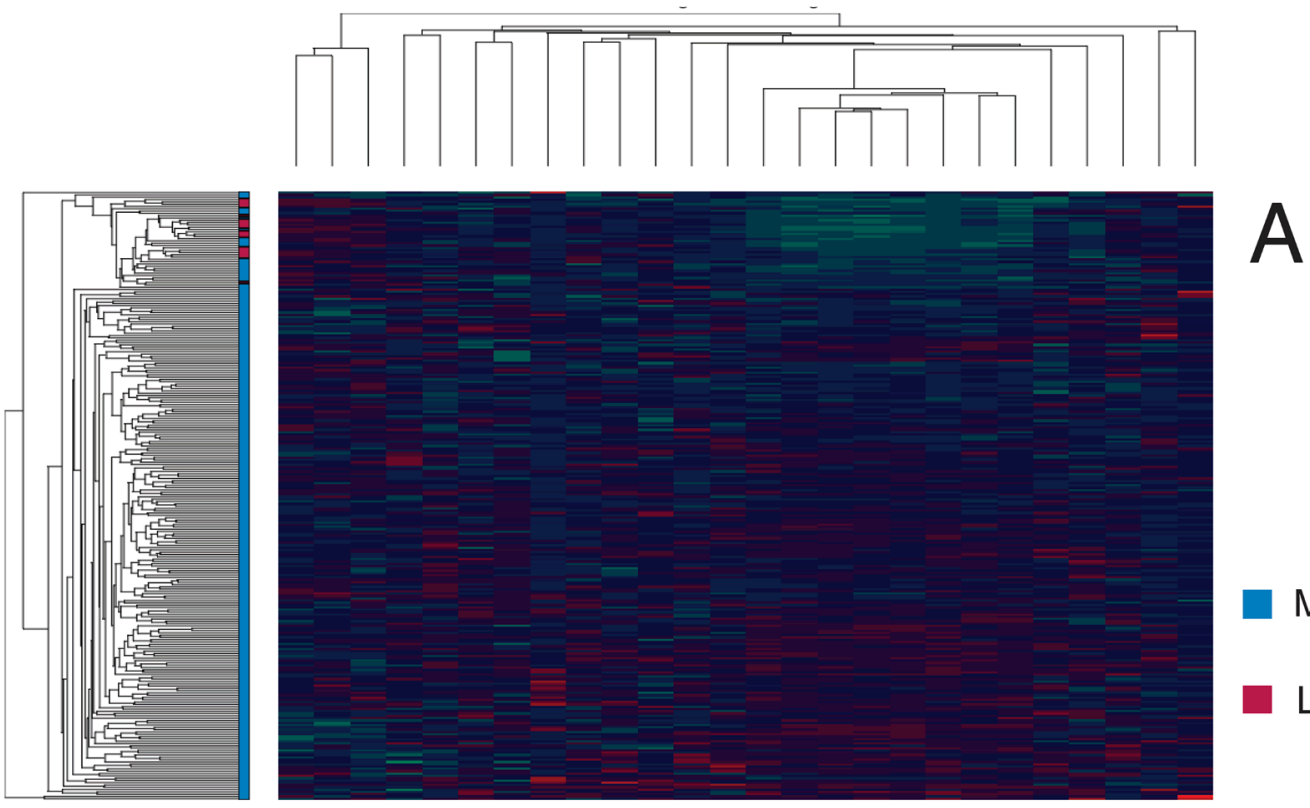

Malignant

LMP
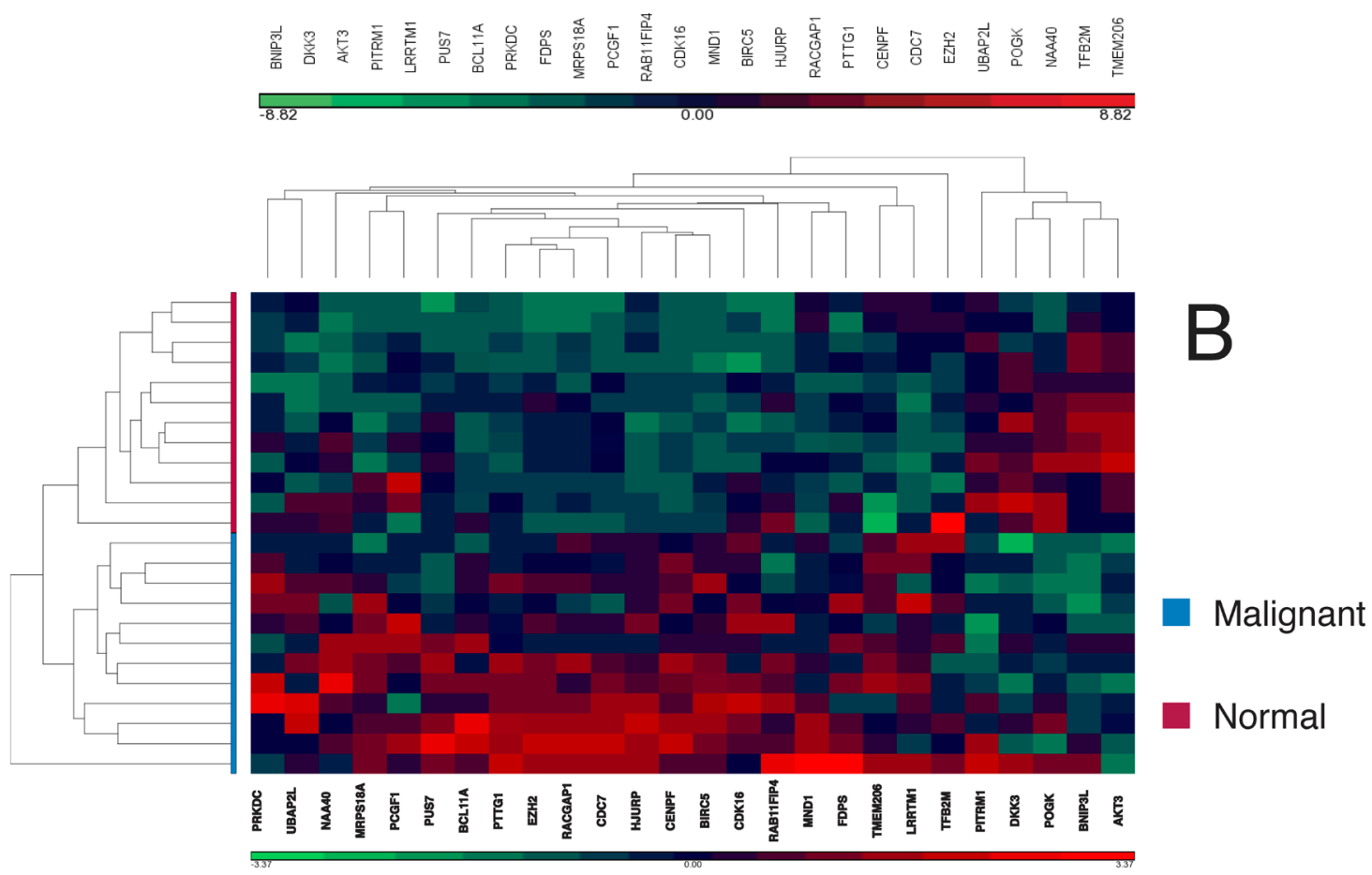

Figure 3: Hierarchical clustering of the 26-genes signature panel and the independent datasets. A) When applied to GSE9899 dataset by Tothill et al., LMP samples are clustered closely. B) Hierarchical clustering clearly distinguishes between normal epithelia and cancer tissues. Further assessment of the gene panel using k-means algorithm is displayed in Figures 4 and 5. 


\section{Pathways and Interactions analysis:}

Pathway enrichment analysis using the 26-genes signature panel (Table 3) identified $10 \mathrm{KEGG}$ annotated human pathways. The results show dysregulation of critical cellular mechanisms and signaling pathways. The dysregulated pathways include endocytosis, focal adhesion, MAPK signaling, PI3K-AKT signaling, and RAS signaling (Table 5). P-values of enrichment analysis are calculated using chi-squared test. The analysis was carried through Partek Software Package and KEGG pathway database. The overlaps of the identified pathways are summarized as a network of dysregulation, with some additional interactions included from STRING database. Figure 6 displays the network and illustrates how each module participates in the enriched pathways and biological functions. Connections of elements are either direct molecular interactions or mediated interactions. Some of the dysregulated genes are shared between multiple pathways. For instance, Caveolins (CAV1, CAV2) are shared between endocytosis and focal adhesion. AKT3, CAV1, CAV2, Platelet Derived Growth Factor Receptor A (PDGFRA), and PDGFRB are shared between four pathways. Those include focal adhesion MAPK, PI3K-AKT, and RAS signaling (Figure 6).

This analysis demonstrates that AKT3 and PDGFRA appear as the central elements in terms of the position in the network, overlaps between the dysregulated pathways, and the fold change magnitude. The results show mRNA
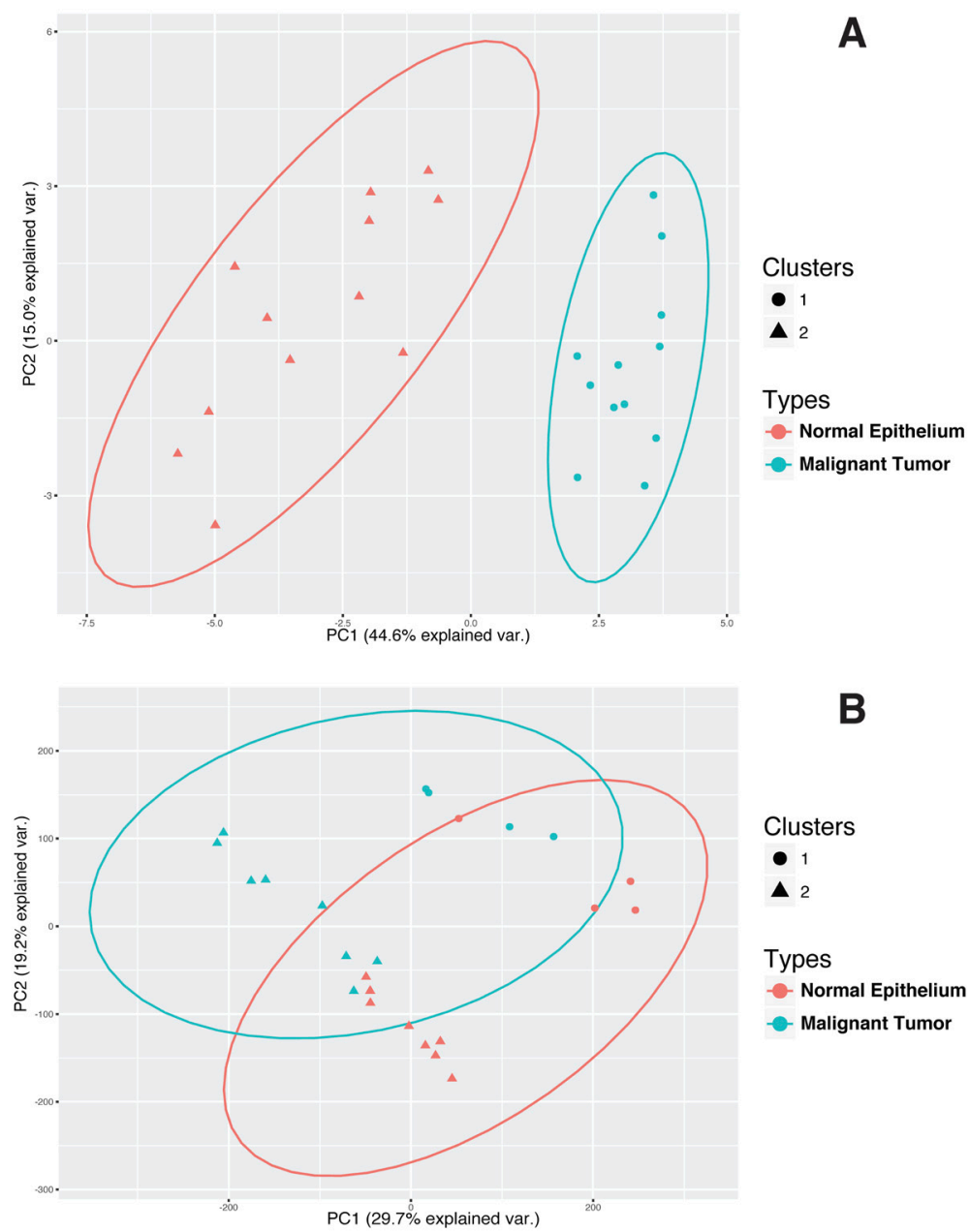

B

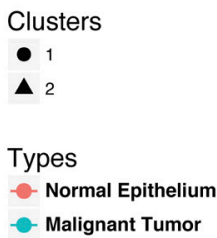

Figure 4: Unsupervised classification of HGSOC and normal epithelial samples. Use of the 26-gene dysregulation panel (Table 3) improves the unsupervised classification of an independent sample set from GSE14407 data. The plot shows the projection of the samples into the first two principal components. A) Two clusters distinctly represent the two tissue types and the groups are completely separated when only the 26-gene dysregulation panel is used. Cluster 1 represents $100 \%$ normal samples and cluster 2 represents $100 \%$ malignant samples. B) The use of all genes for PCA and k-means cannot stratify between the samples, and the clusters represent mixed tissue types. In particular, each cluster is composed of 50\% malignant and 50\% normal samples (Table 4). Overlap of the confidence ellipses indicates that using PCA is not sufficient to distinguish between the two tissue types. The data-point shapes indicate the cluster memberships designated using $\mathrm{k}$-means algorithm for the unsupervised clustering. The ellipses represent the 2 -dimentional $95 \%$ confidence interval for each tissue type. 
downregulation of PDGFRA in MT. Lower mRNA expression of AKT3 are observable in MT compared to BT and NE (Table 2 and Table 3). AKT3 is involved in 8 of the 10 identified pathways - Dopaminergic synapse, Rap1 signaling, Focal adhesion, MAPK, Melanoma, Proteoglycans in cancer, PI3K-AKT, and Ras signaling (Table 5). PDGFRA is associated with 7 of the pathways (supplementary material). Two of the dysregulated genes in MT compared to BT, AKT3 and BCL11, are also involved in the extracted network.

\section{DISCUSSION}

We conducted a comparative analysis of mRNA expression using laser capture micro-dissected ovarian tissues from NE, BT, and MT. Differential expression analysis identifies dysregulated genes that stratify MT from both NE and BT (Tables 2 and 3). The set of four genes AKT3, PTTG1, CENPF, and MND1 are the most significant, based on fold changes, among the dysregulated genes in MT compared to BT and NE (Figure 1). To verify this observation, we utilized two independent publicly available datasets (GSE14407 and GSE9899) (Figure 2). Cross-examination results show statistically significant
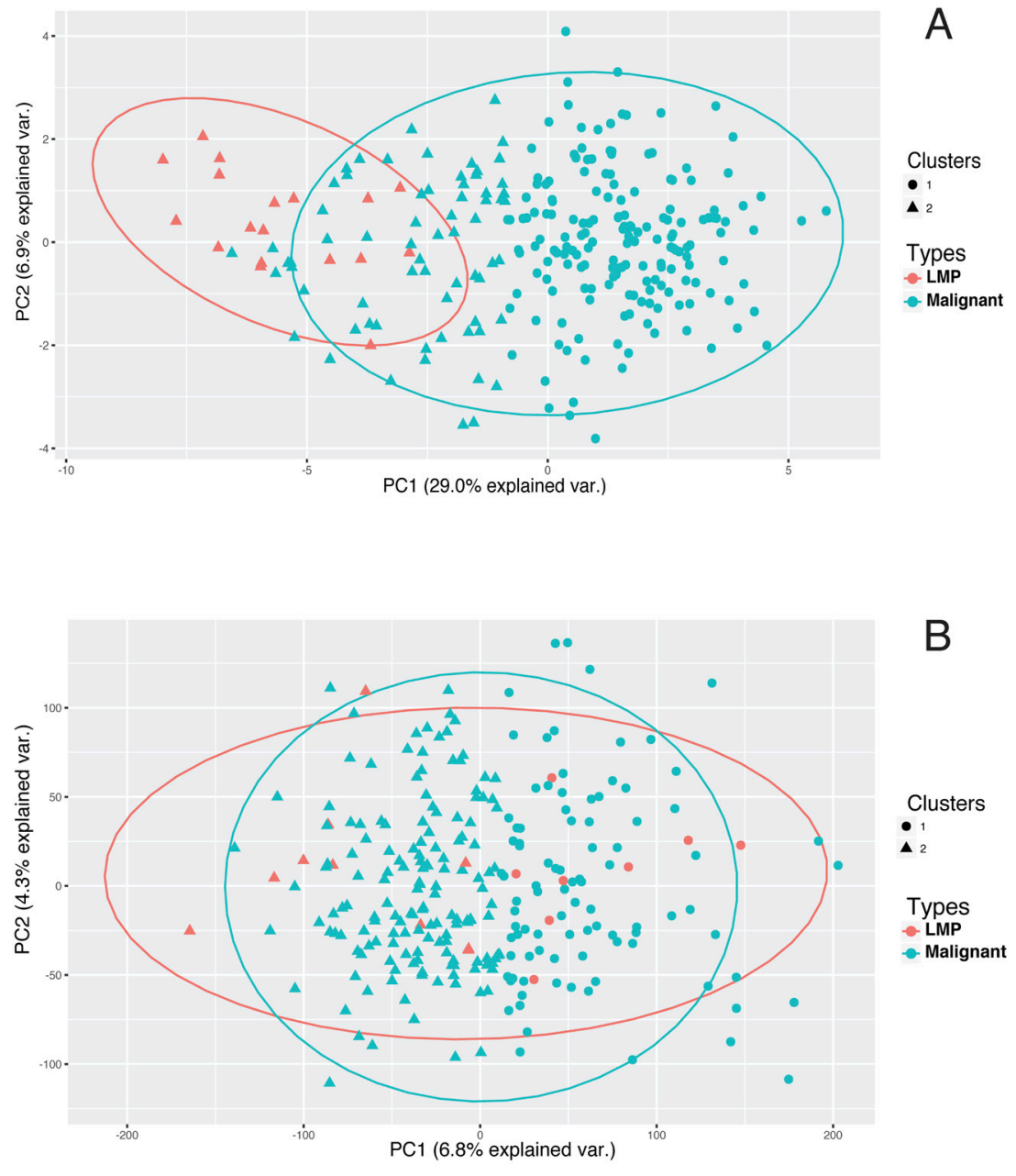

Figure 5: Unsupervised classification of HGSOC and LMPsamples. The use of the 26-gene dysregulation panel(Table 3) improves the classification of an independent sample set from GSE9899 data. The samples are projected into the first two principal components. A) By using the 26-gene signature panel, unsupervised clustering stratifies LMP samples into the same group while the other group consists only of malignant samples (Table 4). In particular, LMP samples are allocated only to the cluster 2 . Also, the clusters 1 and 2 represent approximately $72 \%$ and $28 \%$ of the malignant samples, respectively. In this case, the two principal components explain $35.9 \%$ of the variance in the data B) The use of all genes for PCA and k-means cannot stratify between the samples, and the clusters represents mixed tissue types as the confidence ellipsoids majorly overlap (Table 4). In particular, LMP samples are allocated to both clusters. Also, the clusters 1 and 2 represent approximately $38 \%$ and $62 \%$ of the malignant samples, respectively. In this case, the amount of data variance explained by the first two principal components drops to $11.1 \%$. Data-point shapes indicate the cluster memberships designated using k-means algorithm. The ellipses represent the 2-dimentional $95 \%$ confidence interval for each tissue type. 
evidence of consistent dysregulations of four genes (Figure 2). The distinguishing expression patterns of these genes, between the different pathological states, suggest potential roles as indicators of HGSOC malignancy. Prior studies support the roles of some of these genes in ovarian cancer. PTTG1 is a therapeutic target in ovarian cancer and is associated with functions including DNA repair, angiogenesis, and cell development [22, 23]. CENPF expression has been associated with cell cycle progression, and malignancy through FOXM1 [20, 24]. To our knowledge, AKT3 downregulation and MND1 upregulation have not been previously reported in human HGSOC.

While dysregulations of the set of fours genes are significant between MT vs BT and NE, there are also some detectable dysregulation between $\mathrm{BT}$ and $\mathrm{NE}$ (Figures 1 and 2B). As the dysregulations indicate the tumor presence, their intensity can determine whether the tumors are malignant or not. Moderate dysregulation of BT as compared to NE is supported by the fact that benign tumors exhibit functional similarities with malignant tumors, including evading growth suppression and resisting cell death $[14,16]$. However, malignant tumors are expected to exhibit more extreme dysfunctions as well as other unique characteristics such as metastasis [14]. In our study, enrichment analysis results of the 26 dysregulated signature gene panel (MT vs BT and NE) identified G2M checkpoint and E2F transcription factor cell cycle-related targets, which are related with P53 activities $[25,26]$. These results are supported by the reports of HGSOC displaying P53 mutations in more than $70 \%$ of cases $[1,27]$, compared to dramatically lower rates in low malignant potential tumors [28].

The classification results display the utility of the 26-gene signature panel to distinguish between MT and both BT and NE when the signals are combined (Figure 4 and 5, Table 4). PCA combines mRNA signals and represent the microarray samples in a lower dimensional space, which allows for an interpretable feature selection. k-means clustering shows that the 26-genes panel stratify the PCA-projected samples, based on their respective tissue types (Figures 4A and 5A). In a similar procedure, without filtering the input mRNA signals, the classification algorithm loses its stratification power (Table 4). This observation indicates that the comparative analysis of LCM samples generates a focused and meaningful outline of the genetic dysregulations necessary for identification of HGSOC. As HGSOC is known to encompass a diverse genetic profile, the results show how the use of mRNA panel boosts the classification quality and addresses the issue of genetic heterogeneity. This also indicates that the signature mRNA panel can contribute to the design

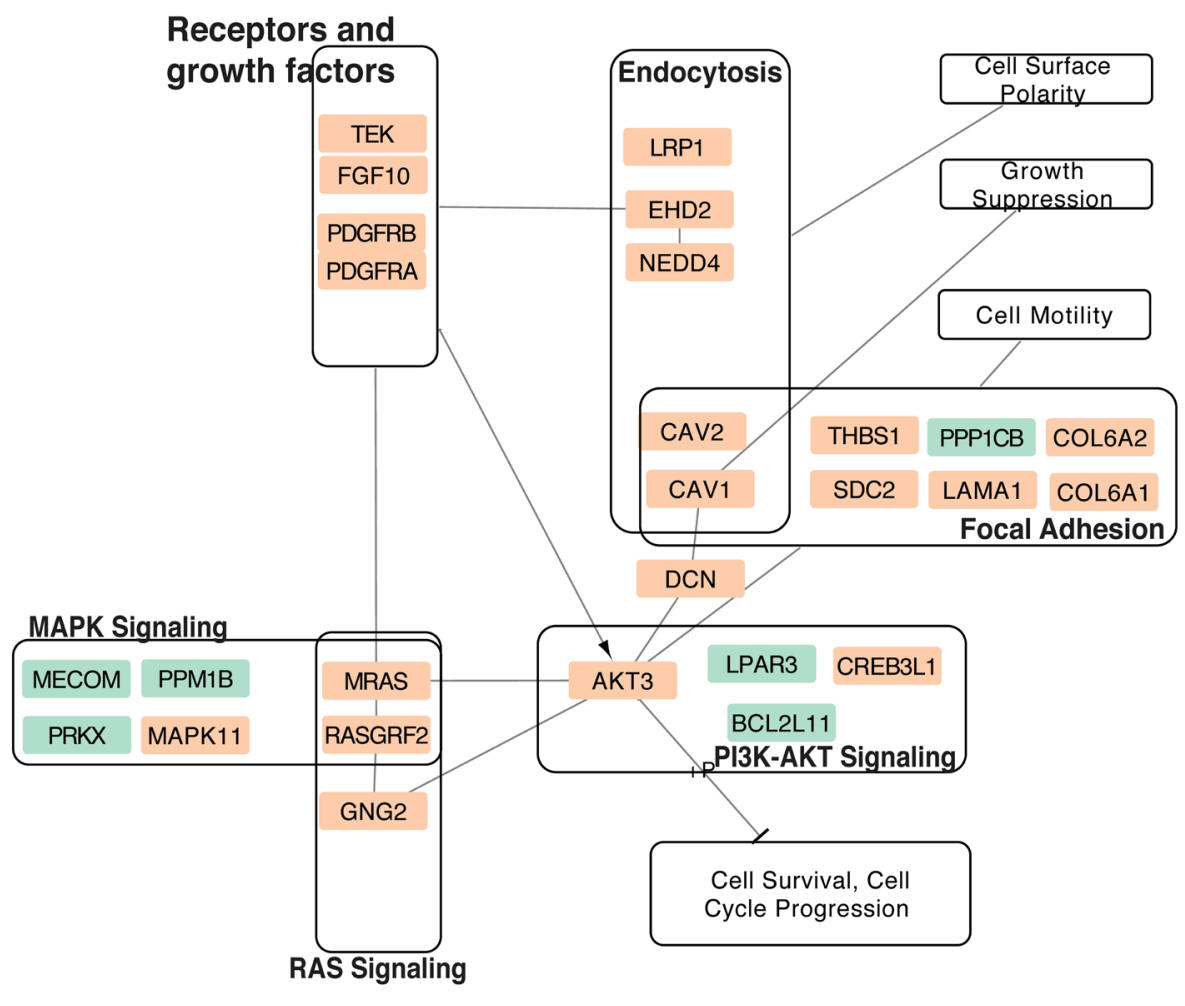

Figure 6: Overlap of enriched pathways from MT vs. NE differential expression. Multiple pathways either directly or indirectly regulate AKT3, which is also dysregulated in BT as compared to MT (Table 3). In addition, the receptors and growth factor affect a majority of enriched pathways. Orange nodes represent downregulated transcripts, and the green nodes represent upregulated transcripts. STRINGDB dataset was used to include additional Protein-Protein Interactions (supplementary material). 
Table 4: Unsupervised k-means clustering of the two independent datasets, GSE9899 and GSE14407, using a 2-dimensional PCA projection of the dysregulated 26-gene panel.

\begin{tabular}{|l|l|l|l|l|l|}
\hline \multicolumn{2}{c}{} & \multicolumn{2}{l|}{ PCA Dysregulated Genes } & PCA All Genes & Cluster 2 \\
\cline { 3 - 7 } \multicolumn{2}{c|}{} & Cluster 1 & Cluster 2 & Cluster 1 & 8 \\
\hline \multirow{2}{*}{$\begin{array}{l}\text { Bowen et al. } \\
\text { GSE14407 }\end{array}$} & Normal & 12 & 0 & 4 & 8 \\
\cline { 2 - 7 } & Cancer & 0 & 12 & 4 & 10 \\
\hline $\begin{array}{l}\text { Tothill et al. } \\
\text { GSE9899 }\end{array}$ & LMP & 0 & 18 & 8 & 153 \\
\cline { 2 - 7 }
\end{tabular}

of future collective biomarkers as alternative to singlemolecule biomarkers.

Pathway enrichment analysis identifies functional associations of the dysregulated genes, and shows major overlaps among the ten enriched KEGG pathways (Table 5, Figure 6). In particular, AKT3 appears in 8 and PDGFRA appears in 7 of the 10 pathways. PDGFRA is connected to AKT3 activity and regulations in participates in cancer related mechanisms [29]. PDGFRA alteration is associated with ovarian cancer but not frequently mutated $[30,31]$. This suggests that the interconnections between AKT3 and PDGFRA are potential for future studies. The extracted network of pathway overlaps shows associations of HGSOC dysregulation with several critical cancer mechanisms, including cell survival, cell motility, and tumor growth. Additional evidence from the literature indicates that endocytosis and focal adhesion components of this network are involved in Epithelial-Mesenchymal Transition (EMT), and cell motility [32-34].

Based on the dysregulation patterns and functional associations, our results indicate that AKT3 is a potential central marker of tumor presence and malignancy. AKT3 is one of the 3 major protein kinase $\mathrm{B}$ isoforms, and exhibits high levels of homology to the other members of the AKT family (AKT1 and AKT2), particularly in the highly conserved phosphorylation sites [35]. AKTs are frequently dysregulated in ovarian cancer, and participate in various cancer associated activities, including proliferation, migration, survival, and apoptosis [35-41]. While AKT3 is relatively understudied compared to the other members of AKT family, its downregulation is to some extent contrary to the early literature [39, 42, 43]. Earlier studies reported upregulation of AKT molecules in breast, prostate, and ovarian cancers [35, 39, 42, 43]. However, our results show that AKT3 is downregulated, which is also supported by more recent studies. Phung et al. showed that AKT3 inhibits growth in vascular tumors and displays declined expression [40]. Grottke et al. also showed that AKT3 downregulation results in elevated migration and metastasis in breast cancer [44]. Based on validation in independent public datasets (GSE9899 and GSE14407), we conclude that AKT3 downregulation in HGSOC implies opposing patterns compared to reports of AKT1 and AKT2 [20]. In addition, we identify AKT3 as a potential central marker of tumor malignancy, as its levels in BT are slightly lower than in NE, and significantly further decreased in MT compared to BT (Figure 2). Nakatani et al. reported that AKT3 enzyme activity levels correlate with its upregulated mRNA levels in breast cancer and prostate cancer [39]. This finding, along with our results, suggests that AKT3 mRNA downregulation could reduce its protein phosphorylation activity and potentially can be used to establish a strong HGSOC biomarker. In addition, AKT3 downregulations might contribute to tumor growth, metastasis, and cell migration in HGSOC [40, 44]. We conclude that further study of AKT3 activities in ovarian cancer will lead to new insights of the signaling activities, especially those related to the PI3K-AKT pathway.

The results presented in this article display how the comparative investigation of mRNAs provides signatures for identifying HGSOC relative to both normal epithelia and benign tumors. Coupled with pathway analysis, we determine functional dysregulations associated with these signatures. The activities of the dysregulated genes and their causal relationships need to be further investigated using other molecular aspects such as protein assays, DNA methylation, and phosphorylation. The significant changes in mRNA levels of the 26-gene signature panel indicate their potential as biomarkers for HGSOC, due to their specificity to malignant tissues. We showed how the dysregulated genes could be used as molecular signatures to stratify HGSOC (Figure 2). These molecular signatures can potentially be used to enhance early detection for HGSOC and ultimately contribute to managing mortality rates.

\section{MATERIALS AND METHODS}

Our initial in-house data set consists of 24 cell specific samples processed through LCM, 10 normal epithelial tissues (NE), 8 malignant tumor tissues (MT), and 6 benign tumor tissues (BT) (Table 1). In addition, we utilized two related and independently collected datasets for verification of results in larger datasets, GSE14407 and GSE9899. GSE14407 consists of 12 normal ovarian epithelial tissues and 12 ovarian malignant tumor tissues. GSE9899 includes 18 low malignant potential samples and 246 HGSOC samples. Our in-house data is publicly available through NCBI Gene Expression Omnibus using reference code GSE 29156. Non-tumorous ovarian epithelial tissues, and tumor tissues from benign and 
Table 5: Pathway Enrichment Analysis of differentially expressed genes comparing NE and MT

\begin{tabular}{|l|l|l|l|}
\hline Pathway Name & P-value & $\begin{array}{l}\text { Percentage of pathway genes } \\
\text { dysregulated }\end{array}$ & $\begin{array}{l}\text { Number of dysregulated genes } \\
\text { in pathway }\end{array}$ \\
\hline Proteoglycans in cancer & $4.13 \mathrm{E}-07$ & 5.38 & 12 \\
\hline Focal adhesion & $1.98 \mathrm{E}-05$ & 4.93 & 10 \\
\hline Dopaminergic synapse & $9.97 \mathrm{E}-05$ & 5.47 & 7 \\
\hline PI3K-Akt signaling pathway & 0.00013 & 3.83 & 13 \\
\hline Rap1 signaling pathway & 0.00034 & 4.32 & 9 \\
\hline MAPK signaling pathway & 0.00065 & 3.91 & 10 \\
\hline Ras signaling pathway & 0.00084 & 4.04 & 9 \\
\hline Amphetamine addiction & 0.0014 & 6.06 & 4 \\
\hline Vitamin B6 metabolism & 0.0016 & 16.7 & 1 \\
\hline Endocytosis & 0.0018 & 4.00 & 8 \\
\hline Melanoma & 0.0024 & 5.71 & 4 \\
\hline
\end{tabular}

malignant serous carcinoma samples were analyzed with GeneChip Affymetrix Human Exon 1.0 ST arrays. Gene expressions were subsequently subjected to multiple statistical procedures for production of accurate and quality results.

\section{Tissue collection}

Ovarian specimens were obtained, under IRB approved guidelines at Carolinas Medical Center (CMC), during surgery for ovarian cancer or other gynecologic conditions. The samples were classified as normal ovary, benign tumors, or malignant tumors. Malignant tissues were from patients with serous carcinoma at stage II or III, grade 3 according to pathological diagnosis assigned by pathologists at CMC using the World Health Organization criteria for ovarian tumors (Table 1). Tissue samples were placed in a standard sized cryomold (Sakura Finetek USA, Inc., Torrance, CA), covered with Optimal Cutting Temperature (OCT) compound (Sakura Finetek USA, Inc., Torrance, CA), frozen and stored at $-80^{\circ} \mathrm{C}$ [19].

\section{Laser Capture Microdissection (LCM)}

OCT embedded samples were serially sectioned into $8 \mu \mathrm{m}$ sections and prepared for LCM using the HistoGene LCM Frozen Section Staining kit (Applied Biosystems, Life Technologies, Co., Carlsbad, CA) according to the manufacturer's protocols. The stained sections were immediately micro-dissected by an Arcturus ${ }^{\circledR}$ PixCell ${ }^{\circledR}$ IIe LCM (Molecular Devices, LLC, Sunnyvale, CA). Normal epithelium and tumor cells were separately collected from appropriate sections. RNA quality was determined using the residual slide materials [19].

\section{cDNA Synthesis and Amplification}

Single primer isothermal amplified (SPIA) complimentary DNA (cDNA) was generated and amplified using the Whole Transcriptome WT-Ovation Pico RNA Amplification System Kit (NuGEN Technologies Inc., San Carlos, CA), and was used for microarray sample preparation.

\section{Exon Microarray and Sample Hybridization}

$3 \mu \mathrm{g}$ of SPIA amplified cDNA was used to do the sense-strand cDNA (ST-cDNA) conversion using the WTOvation Exon Module (NuGEN Technologies Inc., San Carlos, CA). $5 \mu \mathrm{g}$ ST-cDNA was fragmented and labeled with FL-Ovation cDNA Biotin Module V2 kit (NuGEN Technologies Inc., San Carlos, CA) and hybridized using Affymetrix Human Exon 1.0 ST arrays (Affymetrix, Inc., Santa Clara, CA). Microarray hybridization and scanning was performed using GeneChip Hybridization Oven 640, GeneChip Fluidics Station 450, and GeneChip Scanner $30007 \mathrm{G}$ with Autoloader respectively (Affymetrix, Inc., Santa Clara, CA) [19].

\section{Statistical Analysis}

The samples were analyzed using Partek ${ }^{\circledR}$ Genomics Suite ${ }^{\circledR}$ (Partek Inc., St. Louis, MO). Microarray transcripts were normalized using GCRMA method. Exons were summarized to genes expressions using winsorized mean (below 10.0\% and above 90.0\%) and Tukey's biweight one-step. Differential expression p-values were calculated using Analysis of Variance (ANOVA). Unannotated genes were removed and transcripts passed as significant if their False Discovery Rate (FDR) criteria was less than 0.05 $($ FDR $<0.05)$ (Table 2).

Differentially expressed genes between MT and NE 
were analyzed to determine differentially expressed genes between BT and MT (FDR < 0.05) (Table 3).

\section{Validation and confirmation of results}

We used two publicly available datasets to verify the results. First, we utilized an experimentally similar datasets from Bowen and colleagues which includes 12 normal ovarian epithelial tissues and 12 ovarian tumor tissues each separated using LCM [9]. The samples were obtained through NCBI GEO portal from GSE14407 dataset. Second, we used whole tissue samples by Tothill and colleagues (GSE9899); with samples limited to Low Malignant Potential (LMP) and ovarian serous carcinoma malignant tumors [12]. The samples of GSE9899 that we used included $18 \mathrm{LMBs}$ and 246 malignant tumors. We used hierarchical clustering algorithm using average linkage and Euclidian distance to cluster the samples from GSE14407 and GSE9899. The hierarchical clustering procedure was done using Partek ${ }^{\circledR}$ Genomics Suite ${ }^{\circledR}$. We used Principal Component Analysis (PCA) to evaluate the utility of dysregulated genes between MT and BT compared to all gene transcripts in distinguishing between the sample types (Figures 4 and 5). For each test dataset, we separately applied PCA to all annotated genes and the panel of dysregulated genes. PCA was calculated based on the covariance matrix of gene expressions and the data points were shifted to the mean of zero. For further evaluation, we used k-means algorithm for unsupervised clustering of samples into two groups after applying PCA. For each dataset, the results of k-means were calculated based on whether PCA was done on the dysregulated genes between MT and BT or not. PCA results were projected on the first two principle components. Cross validation of results were done using $\mathrm{R}$ statistical analysis package [45]. Moreover, the statistical significance of the dysregulated gene between MT and BT with fold change magnitude more than 3 were evaluated in the test datasets (Figure 2).

\section{Enrichment Analysis}

Differentially expressed genes in NE vs MT were further analyzed to investigate the underlying functional dysregulations. Overrepresentation analysis of KEGG annotated pathways was performed using Partek $^{\circledR}$ Genomics Suite ${ }^{\circledR}$. Enrichment score of each pathway was calculated based on Chi-squared test of differentially expressed gene in pathway, relative to the total number of the annotated genes of pathway (Table 5). $\mathrm{P}$-values of Chi-squared test were subjected to multiple hypothesis testing criteria (FDR $<0.05$ ). Additional interactions were included by manual examination of the Protein-Protein Interactions (PPI) network of Homo Sapiens. PPIs were obtained using STRING-DB online database [46]. The interactions were included if they had medium or higher confidence based on data input of STRING-DB criteria [46]. Gene Ontology (GO) enrichments and related annotated enrichments were investigated based on MSigDB database by Broad Institute [47]. We used the same statistical criteria (FDR < $0.05)$ as the cut off for reporting enriched terms.

\section{Abbreviations}

BT: Benign Tumors, NE: Normal Epithelia, MT: Malignant Tumors, LCM: Laser Capture Microdissection, LMP: Low Malignant Potential, HGSOC: High-Grade Serous Ovarian Cancer, PCA: Principal Component Analysis.

\section{AUTHORS' CONTRIBUTIONS}

PNY: Conception and design, development of methodology, analysis and interpretation of data, writing, review and/or revision of the manuscript.

CR: Writing, review and/or revision of the manuscript, analysis and interpretation of data.

ZBM: Administrative, technical, or material support, development of methodology, conception and design.

DLT: Acquisition of data, review and/or revision of the manuscript, analysis and interpretation of data.

MTM: Study supervision, writing, review and/or revision of the manuscript, administrative, technical, or material support.

\section{ACKNOWLEDGEMENTS}

We would like to thank the National Cancer Institute for making their publicly available data. Also, we would like to thank extensive and continuous support from Carolinas Healthcare System and the College of Computing and Informatics at UNC Charlotte. We would like to express our gratitude to those who made this study possible by donating their samples.

\section{CONFLICTS OF INTEREST}

Authors declare no potential conflicts of interest.

\section{Ethics approval and consent to participate}

Carolinas HealthCare System IRB\# 05-05-16B.

\section{Availability of data and materials}

The original data used in this study is published and also available in Gene Expression Omnibus. The accession code is GSE 29156. 


\section{REFERENCES}

1. Rosen DG, Yang G, Liu G, Mercado-Uribe I, Chang B, Xiao XS, Zheng J, Xue F-X, Liu J. Ovarian cancer: pathology, biology, and disease models. Frontiers in bioscience: a journal and virtual library. 2009; 14: 2089.

2. Siegel RL, Miller KD, Jemal A. Cancer statistics, 2016. CA: a cancer journal for clinicians. 2016; 66: 7-30.

3. Howlader N NA, Krapcho M, Miller D, Bishop K, Altekruse SF, Kosary CL, Yu M, Ruhl J, Tatalovich Z, Mariotto A, Lewis DR, Chen HS, Feuer EJ, Cronin KA (eds) (2016). SEER Cancer Statistics Review, 1975-2013, National Cancer Institute. Bethesda, MD. http://seercancergov/ csr/1975_2013/, based on November 2015 SEER data submission, posted to the SEER web site.

4. Sasaroli D, Coukos G, Scholler N. Beyond CA125: the coming of age of ovarian cancer biomarkers. Biomarkers in medicine. 2009; 3: 275-88.

5. Nguyen L, Cardenas-Goicoechea SJ, Gordon P, Curtin C, Momeni M, Chuang L, Fishman D. Biomarkers for early detection of ovarian cancer. Women's health. 2013; 9: 17187.

6. Su Z, Graybill WS, Zhu Y. Detection and monitoring of ovarian cancer. Clinica Chimica Acta. 2013; 415: 341-5.

7. Buys SS, Partridge E, Black A, Johnson CC, Lamerato L, Isaacs C, Reding DJ, Greenlee RT, Yokochi LA, Kessel B. Effect of screening on ovarian cancer mortality: the Prostate, Lung, Colorectal and Ovarian (PLCO) cancer screening randomized controlled trial. Jama. 2011; 305: 2295-303

8. Jacobs IJ, Menon U, Ryan A, Gentry-Maharaj A, Burnell M, Kalsi JK, Amso NN, Apostolidou S, Benjamin E, Cruickshank D. Ovarian cancer screening and mortality in the UK Collaborative Trial of Ovarian Cancer Screening (UKCTOCS): a randomised controlled trial. The Lancet. 2016; 387: 945-56

9. Bowen NJ, Walker LD, Matyunina LV, Logani S, Totten $\mathrm{KA}$, Benigno BB, McDonald JF. Gene expression profiling supports the hypothesis that human ovarian surface epithelia are multipotent and capable of serving as ovarian cancer initiating cells. BMC medical genomics. 2009; 2: 1.

10. Adib T, Henderson S, Perrett C, Hewitt D, Bourmpoulia D, Ledermann J, Boshoff C. Predicting biomarkers for ovarian cancer using gene-expression microarrays. British journal of cancer. 2004; 90: 686-92.

11. Santin AD, Zhan F, Bellone S, Palmieri M, Cane S, Bignotti E, Anfossi S, Gokden M, Dunn D, Roman JJ. Gene expression profiles in primary ovarian serous papillary tumors and normal ovarian epithelium: identification of candidate molecular markers for ovarian cancer diagnosis and therapy. International Journal of Cancer. 2004; 112: 1425 .

12. Tothill RW, Tinker AV, George J, Brown R, Fox SB, Lade S, Johnson DS, Trivett MK, Etemadmoghadam D, Locandro
B. Novel molecular subtypes of serous and endometrioid ovarian cancer linked to clinical outcome. Clinical Cancer Research. 2008; 14: 5198-208.

13. Welsh JB, Zarrinkar PP, Sapinoso LM, Kern SG, Behling CA, Monk BJ, Lockhart DJ, Burger RA, Hampton GM. Analysis of gene expression profiles in normal and neoplastic ovarian tissue samples identifies candidate molecular markers of epithelial ovarian cancer. Proceedings of the National Academy of Sciences. 2001; 98: 1176-81.

14. Hanahan D, Weinberg Robert A. Hallmarks of Cancer: The Next Generation. Cell. 2011; 144: 646-74.

15. Roskelley CD, Bissell MJ. The dominance of the microenvironment in breast and ovarian cancer. Seminars in Cancer Biology. 2002; 12: 97-104.

16. Lazebnik Y. What are the hallmarks of cancer? Nature Reviews Cancer. 2010; 10: 232-3.

17. Bowtell DD, Böhm S, Ahmed AA, Aspuria P-J, Bast Jr RC, Beral V, Berek JS, Birrer MJ, Blagden S, Bookman MA. Rethinking ovarian cancer II: reducing mortality from highgrade serous ovarian cancer. Nature Reviews Cancer. 2015; 15: 668-79.

18. Espina V, Wulfkuhle JD, Calvert VS, VanMeter A, Zhou W, Coukos G, Geho DH, Petricoin EF, Liotta LA. Lasercapture microdissection. Nature protocols. 2006; 1: 586603.

19. Tait DL, Bahrani-Mostafavi Z, Vestal CG, Richardson C, Mostafavi MT. Downregulation of HOXC6 in serous ovarian cancer. Cancer investigation. 2015; 33: 303-11.

20. TCGA. Integrated genomic analyses of ovarian carcinoma. Nature. 2011; 474: 609-15.

21. Bowen NJ, Logani S, Dickerson EB, Kapa LB, Akhtar M, Benigno BB, McDonald JF. Emerging roles for PAX8 in ovarian cancer and endosalpingeal development. Gynecologic oncology. 2007; 104: 331-7.

22. Panguluri SK, Yeakel C, Kakar SS. PTTG: an important target gene for ovarian cancer therapy. Journal of ovarian research. 2008; 1: 1.

23. Puri R, Tousson A, Chen L, Kakar SS. Molecular cloning of pituitary tumor transforming gene 1 from ovarian tumors and its expression in tumors. Cancer letters. 2001; 163: 1319.

24. Aytes A, Mitrofanova A, Lefebvre C, Alvarez MJ, CastilloMartin M, Zheng T, Eastham JA, Gopalan A, Pienta KJ, Shen MM. Cross-species regulatory network analysis identifies a synergistic interaction between FOXM1 and CENPF that drives prostate cancer malignancy. Cancer cell. 2014; 25: 638-51.

25. Polager S, Ginsberg D. p53 and E2f: partners in life and death. Nature Reviews Cancer. 2009; 9: 738-48.

26. Taylor WR, Stark GR. Regulation of the G2/M transition by p53. Oncogene. 2001; 20: 1803-15.

27. Ahmed AA, Etemadmoghadam D, Temple J, Lynch AG, Riad M, Sharma R, Stewart C, Fereday S, Caldas C, DeFazio A. Driver mutations in TP53 are ubiquitous in 
high grade serous carcinoma of the ovary. The Journal of pathology. 2010; 221: 49-56.

28. Kmet LM, Cook LS, Magliocco AM. A review of p53 expression and mutation in human benign, low malignant potential, and invasive epithelial ovarian tumors. Cancer. 2003; 97: 389-404.

29. Andrae J, Gallini R, Betsholtz C. Role of platelet-derived growth factors in physiology and medicine. Genes \& development. 2008; 22: 1276-312.

30. Lassus H, Sihto H, Leminen A, Nordling S, Joensuu $\mathrm{H}$, Nupponen NN, Butzow R. Genetic alterations and protein expression of KIT and PDGFRA in serous ovarian carcinoma. British journal of cancer. 2004; 91: 2048-55.

31. Henriksen R, Funa K, Wilander E, Bäckström T, Ridderheim $\mathrm{M}$, Öberg K. Expression and prognostic significance of platelet-derived growth factor and its receptors in epithelial ovarian neoplasms. Cancer Research. 1993; 53: 4550-4.

32. Mosesson Y, Mills GB, Yarden Y. Derailed endocytosis: an emerging feature of cancer. Nature Reviews Cancer. 2008; 8: 835-50.

33. Mellman I, Yarden Y. Endocytosis and cancer. Cold Spring Harbor perspectives in biology. 2013; 5: a016949.

34. Sood AK, Coffin JE, Schneider GB, Fletcher MS, DeYoung BR, Gruman LM, Gershenson DM, Schaller MD, Hendrix MJC. Biological significance of focal adhesion kinase in ovarian cancer: role in migration and invasion. The American journal of pathology. 2004; 165: 1087-95.

35. Yuan ZQ, Sun M, Feldman RI, Wang G, Ma X-1, Jiang C, Coppola D, Nicosia SV, Cheng JQ. Frequent activation of AKT2 and induction of apoptosis by inhibition of phosphoinositide-3-OH kinase/Akt pathway in human ovarian cancer. Oncogene. 2000; 19: 2324-30.

36. Irie HY, Pearline RV, Grueneberg D, Hsia M, Ravichandran P, Kothari N, Natesan S, Brugge JS. Distinct roles of Akt1 and Akt2 in regulating cell migration and epithelialmesenchymal transition. The Journal of cell biology. 2005; 171: 1023-34.

37. Yang Z-Z, Tschopp O, Hemmings-Mieszczak M, Feng J, Brodbeck D, Perentes E, Hemmings BA. Protein kinase $\mathrm{B} \alpha / \mathrm{Akt1}$ regulates placental development and fetal growth. Journal of Biological Chemistry. 2003; 278: 32124-31.

38. Chin YR, Yoshida T, Marusyk A, Beck AH, Polyak K, Toker A. Targeting Akt3 signaling in triple-negative breast cancer. Cancer research. 2014; 74: 964-73.

39. Nakatani K, Thompson DA, Barthel A, Sakaue H, Liu W, Weigel RJ, Roth RA. Up-regulation of Akt3 in estrogen receptor-deficient breast cancers and androgen-independent prostate cancer lines. Journal of Biological Chemistry. 1999; 274: 21528-32.

40. Phung TL, Du W, Xue Q, Ayyaswamy S, Gerald D, Antonello Z, Nhek S, Perruzzi CA, Acevedo I, RamannaValmiki R, Rodriguez-Waitkus P, Enayati L, Hochman ML, et al. Akt1 and Akt3 Exert Opposing Roles in the Regulation of Vascular Tumor Growth. Cancer Research.
2015; 75: 40-50.

41. Shayesteh L, Lu Y, Kuo W-L, Baldocchi R, Godfrey T, Collins C, Pinkel D, Powell B, Mills GB, Gray JW. PIK3CA is implicated as an oncogene in ovarian cancer. Nature genetics. 1999; 21: 99-102.

42. Cristiano BE, Chan JC, Hannan KM, Lundie NA, MarmyConus NJ, Campbell IG, Phillips WA, Robbie M, Hannan $\mathrm{RD}$, Pearson RB. A specific role for AKT3 in the genesis of ovarian cancer through modulation of G2-M phase transition. Cancer Research. 2006; 66: 11718-25.

43. Liby TA, Spyropoulos P, Buff Lindner H, Eldridge J, Beeson C, Hsu T, Muise-Helmericks RC. Akt3 controls vascular endothelial growth factor secretion and angiogenesis in ovarian cancer cells. International journal of cancer. 2012; 130: 532-43.

44. Grottke A, Ewald F, Lange T, Nörz D, Herzberger C, Bach J, Grabinski N, Gräser L, Höppner F, Nashan B. Downregulation of AKT3 Increases Migration and Metastasis in Triple Negative Breast Cancer Cells by Upregulating S100A4. PloS one. 2016; 11: e0146370.

45. Team RC. R: A language and environment for statistical computing. R Foundation for Statistical Computing Vienna, Austria. 2017; doi.

46. Szklarczyk D, Franceschini A, Wyder S, Forslund K, Heller D, Huerta-Cepas J, Simonovic M, Roth A, Santos A, Tsafou KP. STRING v10: protein-protein interaction networks, integrated over the tree of life. Nucleic acids research. 2014; doi: gku1003.

47. Subramanian A, Tamayo P, Mootha VK, Mukherjee S, Ebert BL, Gillette MA, Paulovich A, Pomeroy SL, Golub TR, Lander ES. Gene set enrichment analysis: a knowledgebased approach for interpreting genome-wide expression profiles. Proceedings of the National Academy of Sciences of the United States of America. 2005; 102: 15545-50. 